\title{
Technical Note \\ Forest Transition and Metropolitan Transformations in Developed Countries: Interpreting Apparent and Latent Dynamics with Local Regression Models
}

\author{
Leonardo Bianchini ${ }^{1}\left(\mathbb{D}\right.$, Rosanna Salvia $^{2}\left(\mathbb{D}\right.$, Giovanni Quaranta $\left.{ }^{2}{ }^{(}\right)$, Gianluca Egidi ${ }^{1}$, Luca Salvati ${ }^{3, *}$ \\ and Alvaro Marucci ${ }^{1}$ (D) \\ 1 Department of Agricultural and Forestry Sciences (DAFNE), University of Tuscia, Via S. Camillo De Lellis snc, \\ I-01100 Viterbo, Italy; 1.bianchini@unitus.it (L.B.); egidi.gianluca@unitus.it (G.E.); marucci@unitus.it (A.M.) \\ 2 Department of Mathematics, Computer Science and Economics, University of Basilicata, Viale dell'Ateneo \\ Lucano, I-85100 Potenza, Italy; rosanna.salvia@unibas.it (R.S.); giovanni.quaranta@unibas.it (G.Q.) \\ 3 Department of Economics and Law, University of Macerata, Via Armaroli 43, I-62100 Macerata, Italy \\ * Correspondence: luca.salvati@crea.gov.it; Tel.: +39-06-61-57-10; Fax: +39-06-61-57-10-36
}

check for updates

Citation: Bianchini, L.; Salvia, R.; Quaranta, G.; Egidi, G.; Salvati, L.; Marucci, A. Forest Transition and Metropolitan Transformations in Developed Countries: Interpreting Apparent and Latent Dynamics with Local Regression Models. Land 2022, 11, 12. https://doi.org/10.3390/ land11010012

Academic Editor: Alexandru-Ionuţ Petrişor

Received: 30 November 2021 Accepted: 17 December 2021 Published: 22 December 2021

Publisher's Note: MDPI stays neutral with regard to jurisdictional claims in published maps and institutional affiliations.

Copyright: (C) 2021 by the authors. Licensee MDPI, Basel, Switzerland. This article is an open access article distributed under the terms and conditions of the Creative Commons Attribution (CC BY) license (https:// creativecommons.org/licenses/by/ $4.0 /)$.

\begin{abstract}
Metropolitan fringes in Southern Europe preserve, under different territorial contexts, natural habitats, relict woodlands, and mixed agro-forest systems acting as a sink of biodiversity and ecosystem services in ecologically vulnerable landscapes. Clarifying territorial and socioeconomic processes that underlie land-use change in metropolitan regions is relevant for forest conservation policies. At the same time, long-term dynamics of fringe forests in the northern Mediterranean basin have been demonstrated to be rather mixed, with deforestation up to the 1950s and a subsequent recovery more evident in recent decades. The present study makes use of Forest Transition Theory (FTT) to examine spatial processes of forest loss and expansion in metropolitan Rome, Central Italy, through local regressions elaborating two diachronic land-use maps that span more than 80 years (1936-2018) representative of different socioeconomic and ecological conditions. Our study evaluates the turnaround from net forest area loss to net forest area gain, considering together the predictions of the FTT and those of the City Life Cycle (CLC) theory that provides a classical description of the functioning of metropolitan cycles. The empirical findings of our study document a moderate increase in forest cover depending on the forestation of previously abandoned cropland as a consequence of tighter levels of land protection. Natural and human-driven expansion of small and isolated forest nuclei along fringe land was demonstrated to fuel a polycentric expansion of woodlands. The results of a Geographically Weighted Regression (GWR) reveal the importance of metropolitan growth in long-term forest expansion. Forest-urban dynamics reflect together settlement sprawl and increased forest disturbance. The contemporary expansion of fringe residential settlements and peri-urban forests into relict agricultural landscapes claims for a renewed land management that may reconnect town planning, reducing the intrinsic risks associated with fringe woodlands (e.g., wildfires) with environmental policies preserving the ecological functionality of diversified agro-forest systems.
\end{abstract}

Keywords: land-use change; metropolitan gradient; spatial econometrics; agricultural mechanization; Mediterranean

\section{Introduction}

Providing a global interpretation of socio-environmental changes across a development gradient, Forest Transition Theory (FTT) predicts the inherent shift from net forest area loss, typical of emerging economies, to net forest area expansion [1]. This shift is characteristic of advanced economies and is coupled with a generalized recovery of mixed agricultural-wildland ecosystems [2-4]. This process has occurred in recent times via natural regeneration [5], active planting [6-8], or a combination of the two [9]. From this perspective, the notion of 'forest transition' is associated intimately with underlying socioeconomic forces [10], such as urbanization, late industrialization, tourism growth, 
and infrastructural development [11]. The different processes leading to forest transitions clearly depend on the local (territorial) context [12]. Although some generic processes can be identified for affluent countries (Figure 1), regions and districts do not necessarily experience a regular pattern of forest cover change over time, and the causes and effects of forest transitions may vary largely over space [12-14]. For instance, urbanization can determine a forest decline from direct clearcutting or wildfires [15], basically answering to increased housing demand (e.g., because of population growth) or real estate speculation, especially in contexts with less rigid planning rules or adopting new liberal urbanism schemes [16].

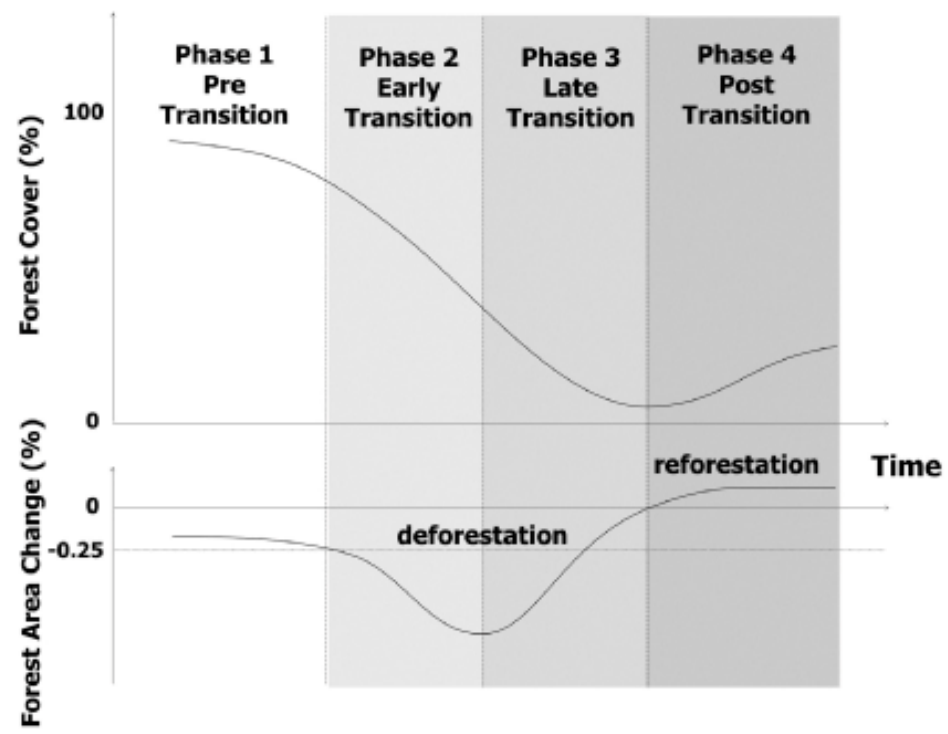

Figure 1. A framework illustrating the Forest Transition Theory (FTT) in advanced economies (Source: authors' elaboration from Rudel et al., 2005).

The predictions of the FTT have been tested empirically at various spatial scales [17-21]. Although the main forces of deforestation act locally, forest transitions in developed countries are far less investigated at that scale, especially in metropolitan regions [22-24]. As a result of urbanization, these regions represent a challenging opportunity to investigate the response of agro-forest landscapes to ecological disturbance and socioeconomic shocks [15,25-27]. Continuous urbanization has reflected the long-term interactions between nature and humans characteristic of the Mediterranean region [7,15,20,25-29]. Following urbanization, the abandonment of cropland, clearcutting, but also wood recolonization in some cases, may result in sequential stages of forest decline and recovery, depending on the local context [30-32]. Wildland-Urban Interfaces (WUIs) in Southern Europe frequently mix low-density settlements with natural habitats [17]. As a result, fringe landscapes feature irregular boundaries with discontinuous, low-density settlements that reflect suburbanization (i.e., population relocation to suburbs) and the delocalization of economic activities in peripheral areas [33]. These fragmented and mixed landscapes derive from a latent (and quite recent) process of peri-urban forest expansion into cropland, shrubland, and pastures [34], which has followed a significant decline in fringe forest cover following compact urban expansion [35]. As a matter of fact, economic development was demonstrated to fuel, in Italy as in Spain, and in Portugal as in Greece, compact urban growth in the 1950s and the 1960s and the uneven expansion of residential, low-density settlements in the 1970s and the 1980s [36-39]. From this perspective, FTT may appropriately predict cyclical trends in forest decline and expansion in complex peri-urban landscapes including relict agro-forest systems [40]. At the same time, predictions of the FTT were compared with those delineated by the City Life Cycle (CLC) theory. This theory provided a classical description of metropolitan cycles in advanced economies [41], explaining-at least indirectly - the socioeconomic dynamics at the base of peri-urban forest decline and 
expansion [38]. CLC indicates different, sequential stages of urban growth forming a cycle of urbanization, suburbanization, counter-urbanization, and re-urbanization [33]. The first two stages, urbanization and suburbanization, have been particularly well studied in Mediterranean Europe [16], and they respectively reflect a compact-dense/mono-centric growth and a low-density, spatially heterogeneous expansion of residential settlements [42].

For the first time, to the best of our knowledge, the present study mixes these two dynamic theories (CLC and FTT) with the aims of (i) improving forest assessment in Mediterranean fringe districts and (ii) informing dedicated planning strategies for the sustainable management of WUIs [2,18,43,44]. Mediterranean forests are widely recognized as an invaluable sink of biodiversity [45], forming green infrastructures that may (indirectly) contain urbanization and the negative externalities of economic activity [34]. However, earlier studies have demonstrated that built-up areas around forests expanded in parallel with a decrease in cropland. In other words, residential settlements and forests act as competing land uses with negative impacts on agricultural systems [5].

Going beyond a model of forest expansion from small nuclei of pristine, high-quality woodlands (concentrated in peripheral districts), recent land-use dynamics reflect a more complex path with the growth of scattered and fragmented forest nuclei embedded in a consolidated network of relict peri-urban and rural woodlands [31,46,47]. The shift from a traditional model of forestation irradiating from a few peripheral locations (hereafter defined as 'mono-centric') to a 'polycentric' structure of forest growth (irradiating from multiple locations even close to cities), may be seen at the base of FTT in Mediterranean contexts [48]. This pattern may inform a refined interpretation of forest transitions in metropolitan regions [39]. This 'polycentric' network of forests is also at the base of green infrastructures, assuring the efficient protection of natural habitats in fringe districts [48].

The present study introduces a refined analysis of long-term changes in forest cover as a result of urban expansion in a large metropolitan area (Rome, Central Italy) representative of compact, mono-centric cities in Southern Europe [33]. Reflecting socio-ecological dynamics that impact ecologically fragile Mediterranean environments, land-use complexity warrants further investigation of forest trends (1936-2018) in light of the FTT and the parallel urban cycle. A particularly long time interval was investigated in this study covering a productive cycle of forests and a period that encompassed various stages of metropolitan growth including urbanization and suburbanization [35]. Peri-urban landscapes surrounding Rome (Central Italy) have been identified as the most dynamic across the country because of city size and human pressure [34], resulting in sequential waves of forest decline and recovery [47]. While 55 Natura 2000 sites involving $22 \%$ of the study area have been recently established in Rome [48], natural land converted to settlements grew by $0.4 \%$ per year during the last half-century, endangering fragile coastal ecosystems more than mountain systems [49].

To check the validity of the polycentric model applied to forest expansion, local econometric estimations based on a Geographically Weighted Regression (GWR) contributed to ascertain the relationship between settlement expansion and changes over time in the composition and morphology of fringe forest landscapes [45]. Being deliberately simplified, our approach tests the shift from a mono-centric model of forest distribution over space toward a more polycentric structure, as hypothesized by Colantoni et al. (2015) [35]. The empirical verification of this hypothesis benefits from a spatially explicit analysis of a dependent variable (percent share of forest cover in total landscape area) and of a predictor, the distance from a central location, which is assumed to represent a metropolitan gradient from central to peripheral locations typical of mono-centric regions [41]. To account for the residual variability that the predictor is unable to explain [16], space was explicitly considered in the econometric specification. The empirical results of this study may inform policy and planning strategies preserving relict agro-forest systems in ecologically sensitive contexts typical of Mediterranean metropolises. 


\section{Methodology}

\subsection{Study Area}

The investigated area is the metropolitan region of Rome $\left(5355 \mathrm{~km}^{2}\right)$, which is an administrative partition of the Latium region (Central Italy) encompassing the previously established province of Rome (NUTS-3 level of the European Nomenclature of Territorial Statistics). The area includes $15 \%$ flat land $(<100 \mathrm{~m}$ at the sea level) and $20 \%$ mountainous land (>600 $\mathrm{m}$ at the sea level). The Simbruini mountains (highest elevation: $1820 \mathrm{~m}$ above sea level), which belong to the Apennine district, are the most important relief in the area (Figure 2, left); the alluvial flat area of the Tiber river is made up of lowlands (the so-called "Agro Romano" district; Figure 2, right). The climate is typically Mediterranean, with rainfalls concentrated in autumn and spring, and mild winter temperatures [35]. The average annual rainfall and mean daily temperature in Rome (1971-2000) were nearly $700 \mathrm{~mm}$ and $17^{\circ} \mathrm{C}$, respectively [47].
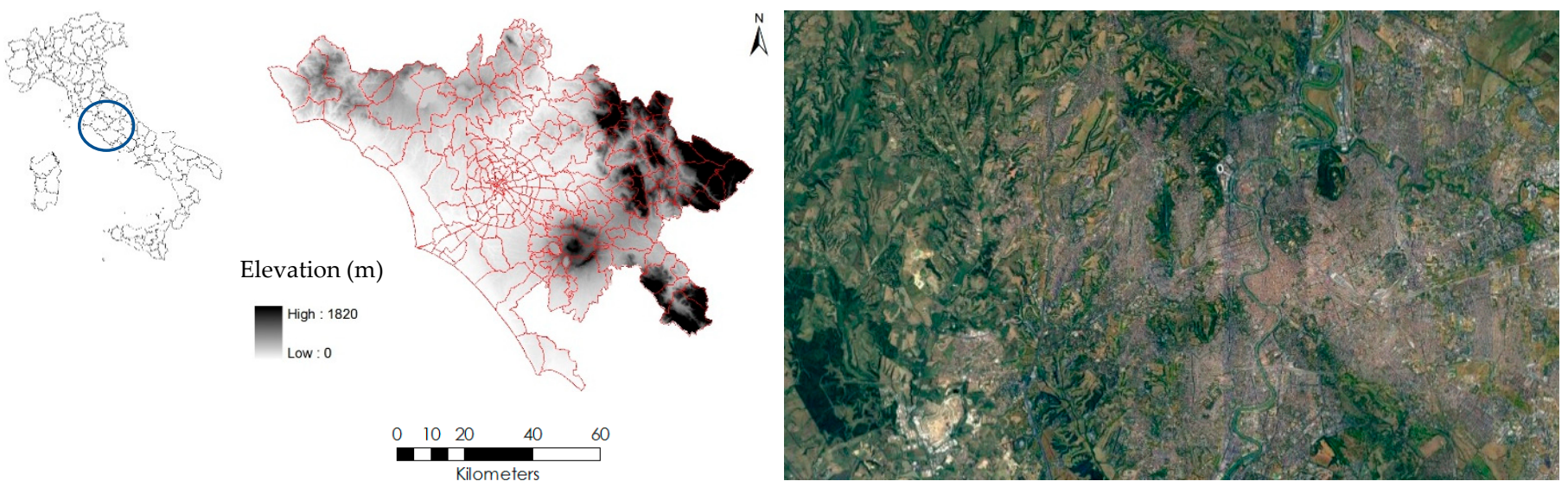

Figure 2. Left: elevation of the study area (meters on the sea level) overlapped with municipalities and urban districts; the insert map represents the position of Rome in Italy; right: a zenith photograph of inner Rome with peri-urban forests (green areas) concentrating on the left side of the landscape scene, courtesy of Google Earth.

The total population almost doubled during the study period from 2 million to 4 million inhabitants [5]. The percent share of the population living in inner Rome in the total population of the study area increased from $20 \%$ to $40 \%$ between 1936 and 2020 [39]. Even though urban settlements are becoming prevalent in the study area, the majority of the province's land is still comprised of forests, pastures, and cultivated fields [45]. Summer wildfires and human pressure, because of Rome expansion, have degraded the pristine forests, but relict woodlands have been sometimes preserved in both flat and hilly areas [48]. Based on official statistics [49], forest composition was changed significantly in the study area. Chestnuts and conifers increased considerably between the mid-1930s and late 2010 s (respectively from $13.8 \%$ to $18.5 \%$ and from $1.7 \%$ to $3.0 \%$ of total forest stock); beech experienced a moderate decline (from $10.1 \%$ to $9.8 \%$ of total forest stock). Cropland abandonment around the central city was the base of natural afforestation uplands [47]; urbanization determined, at the same time, a progressive fragmentation of relict forests around the city, especially along the coastal rim [45]. Industrial areas were traditionally located in the eastern part of the 'Agro Romano' district, while traditional rural areas were (and still are) relatively abundant in the Western side of the study area [49].

Land-use maps were reproduced in Figure 3 to illustrate the mono-centric organization of Rome's metropolitan region, with compact settlements located downtown and a moderate spread of low-density settlements around central locations [34]. The shift toward dispersed urbanization in 2018 was not altering the polarization in central places (downtown Rome) and peripheral districts West and East of Rome [16]. Overall, the study area is administered by 122 municipalities, including the municipality of Rome that encompasses 
the historical city ('within the Aurelian Walls') and the surrounding area $\left(1285 \mathrm{~km}^{2}\right)$ within and outside the main Ring Road ('Grande Raccordo Anulare', GRA). In this study, the central municipality of Rome was further partitioned in 115 local districts (a sort of formal neighborhood known as 'suddivisioni toponomastiche' in Italian, and it is mainly used for statistical reporting at a sub-municipal scale). Following earlier studies [33], the present study made use of a specific (territorial) partition of the area into 236 elementary spatial units that derive from the union (i.e., spatial merging) of 121 municipalities (excluding Rome) and 115 local districts in Rome.

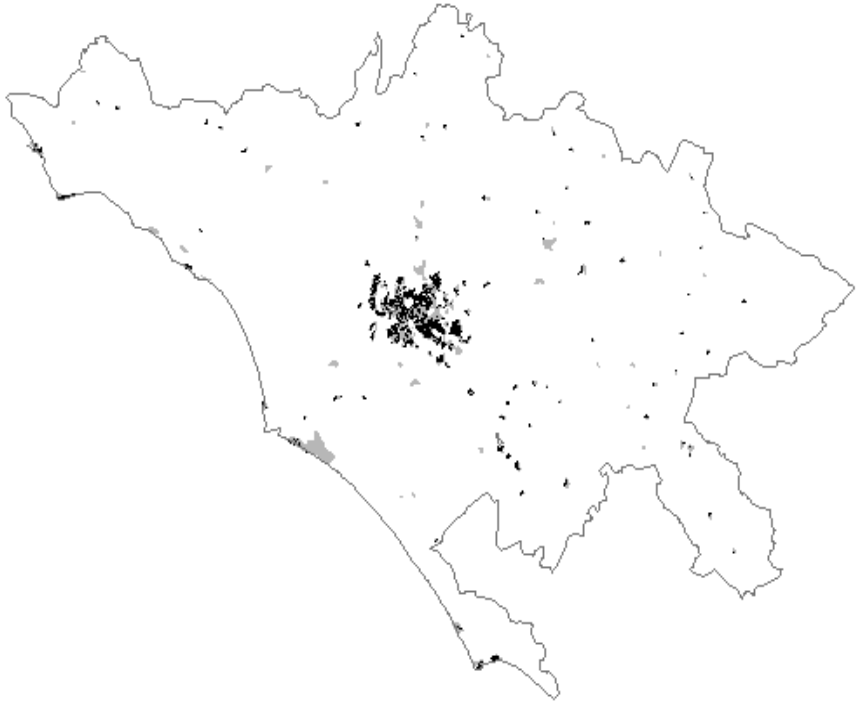

- Compact urban fabric Dispersed urban fabric
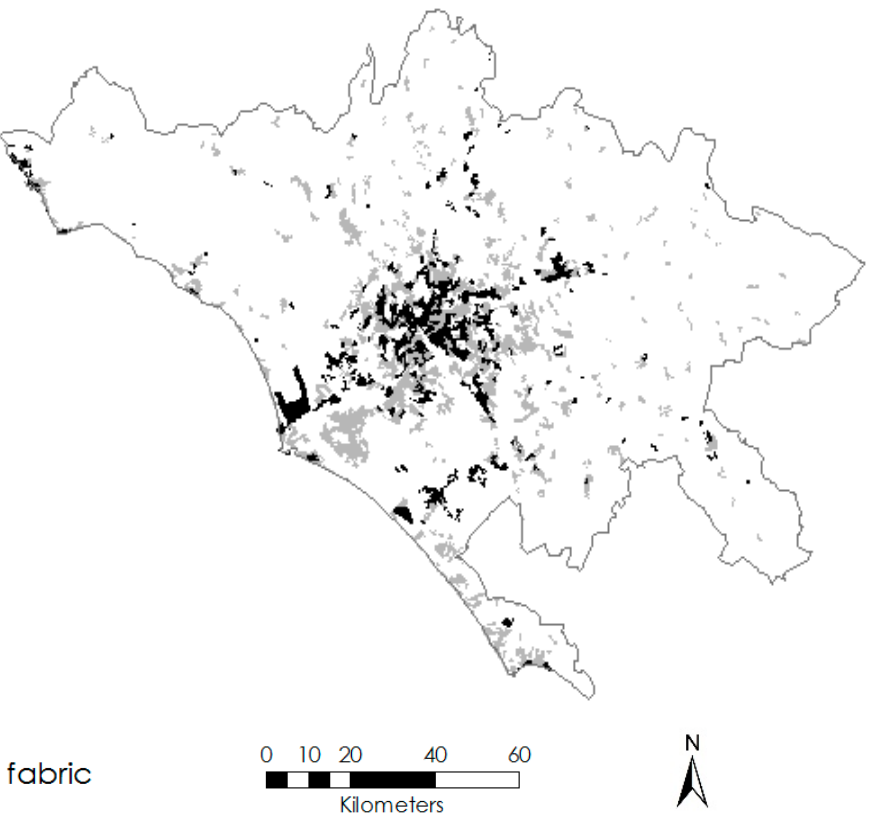

$\stackrel{N}{\Lambda}$

Figure 3. The spatial distribution of the compact and dispersed urban fabric in the study area in the early 1960s (left) and late 2010s (right), based on the elaboration on a local land cover map for 1960 and Corine Land Cover database for 2018.

\subsection{Forest Maps}

Two forest maps spanning the time frame between 1936 and 2018 and presenting a comparable spatial resolution and forest definition were used here. The former source is the Forest Map realized at 1:100,000 scale by 'Milizia Forestale', the Italian Forest Service during the Fascist period, as part of a forest inventory dated 1936 and recently disseminated in digital format (shapefile). The latter source is a Corine Land Cover (CLC) digital map dated 2018 and adopting a legend of 44 land-use classes at a 1:100,000 scale. Polygons classified as CLC 3.1 type ('forests') were extracted and elaborated (Figure 4). The information accuracy of the two maps and the reliability of the forest cover measured for both 1936 and 2018 were internally checked considering additional data that provided estimates of forest area in Rome: (i) the long-term annual forest survey carried out by Italian National Institute of Statistics (Istat), (ii) the two national forest inventories run in 1985 and 2003, (iii) a 25,000 topographic map produced by Italian Military Geographic Institute (Florence) and referring to 1949, (iv) a land map produced by National Research Council (CNR) at 1:200,000 scale and referring to the early 1960s [50], (v) four CLC maps dated 1990, 2000, 2006, and 2012, and (vi) the 1:25,000 land-use maps of Latium produced for 1999 and 2016 by the Cartographic Service of the Regional Authority of Latium region through the interpretation of digital ortho-photographs. 

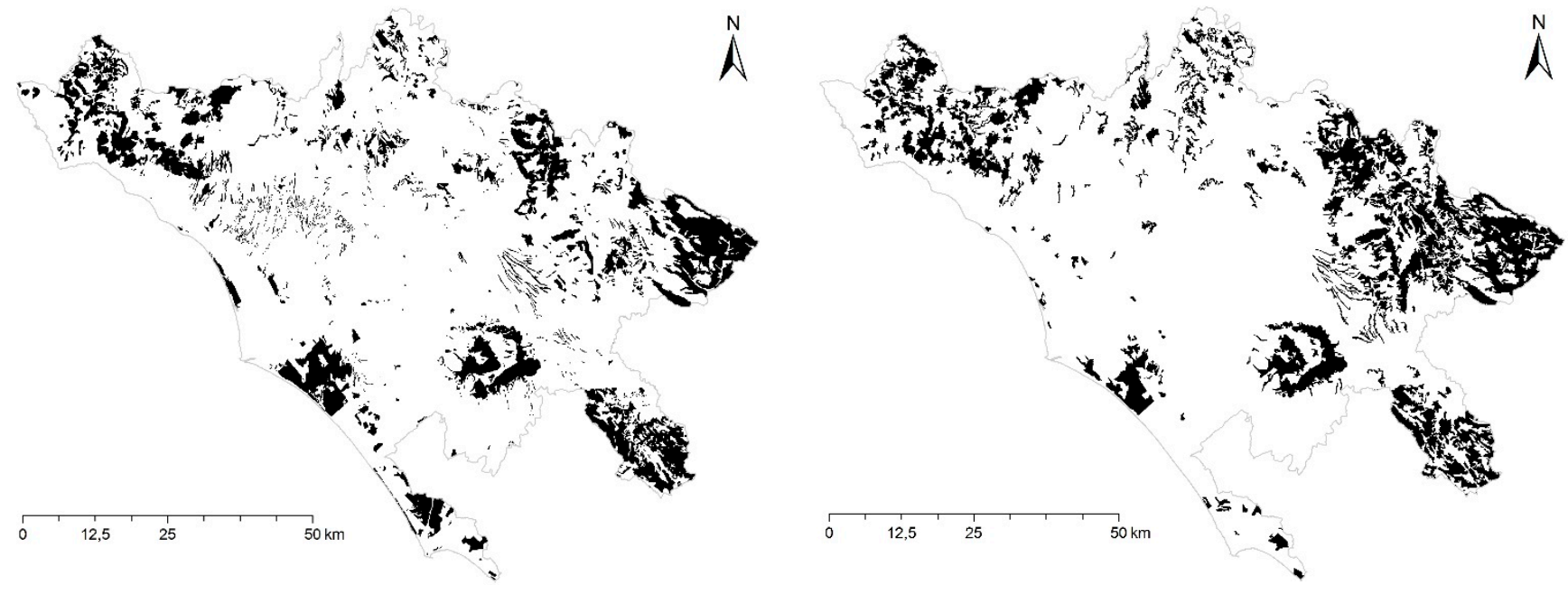

Figure 4. The spatial distribution of forest cover in the study area in 1936 (left) and in 2018 (right), based on elaboration on the forest maps described above.

\subsection{Logical Framework}

To test the inherent shift toward a 'polycentric' model of forest expansion (Colantoni et al. 2015), the percent of forest land area in the total landscape (i.e., municipal/district area) was derived, for each elementary analysis' unit, from the spatial overlay of a shapefile map illustrating the boundaries of the selected domains $(n=236$ municipalities/local districts, see above) separately with each forest map (1936 and 2018). The average distance of each spatial unit (polygon) from downtown Rome was computed as the linear distance of the polygon centroid from a central place in the historical city-considered the heart of political, social, economic, touristic, and cultural life [16]. Adopting administrative boundaries as the elementary unit of investigation gave room to reliable comparisons with official statistics and constitutes a relevant domain for planning purposes [34]. In this study, we assumed Rome's metropolitan region as a laboratory of forest transitions [47], e.g., hypothesizing a classical ('mono-centric') model of forest decline around settlements and forest expansion in peripheral districts, and testing a possible shift toward a more 'polycentric' model of forest expansion around suburban settlements [48]. To verify such assumptions, changes over time in the spatial distribution of forest land along the urban gradient were analyzed comparing the results of spatially implicit and spatially explicit regressions that test the predictions of the FTT at a local scale [5]. More specifically, global and local regressions assessed the empirical relationship between percent forest area (dependent variable) and the distance from downtown Rome (predictor) at two times (1936 and 2018). We assumed a linear and spatially homogeneous relationship between the two variables in a 'mono-centric' model of forest expansion (i.e., a low percentage of forest area close to the inner city that increases with the distance from the city itself). With 'poly-centric' forest expansion [35], the relationship between the two variables is expected to be less polarized along the metropolitan gradient, with the predictor's impact varying largely across space [33]. The highest impact can be reflective of a local context (directly or indirectly) supporting forest expansion [5].

\subsection{Statistical Analysis}

Following the logical framework exposed above, both spatially implicit and explicit models, estimated separately for two time points (1936 and 2018) have been adopted to interpret long-term forest expansion/decline and the underlying territorial dynamics along the metropolitan gradient in Rome. A preliminary check of the linear or non-linear relationship between forest cover and distance from downtown Rome was performed using parametric (Pearson) and non-parametric (Spearman) pair-wise correlation coefficients, testing for significance at $p<0.05$. A detailed description of the regression techniques 
subsequently adopted to test the polycentric expansion of forests has been provided in the following two paragraphs, distinguishing global from local approaches.

\subsubsection{Global Approaches}

Spatially implicit global approaches adopted in this study included Ordinary Least Square (OLS) regressions using linear and non-linear specifications, namely first (linear), second-order (squared), and third-order (cubic) forms. More specifically, the mono-centric structure was first tested adopting a linear specification [33] estimated through logarithmic transformations of both dependent and predictor variables as follows:

$$
F=a+b(D)+e
$$

where $\mathrm{F}$ is the percent share of forest cover in total landscape, $\mathrm{D}$ is the distance of each spatial unit from downtown Rome ( $\mathrm{km}, \log$-transformed), $\mathrm{a}$ and $\mathrm{b}$ are the regression coefficients, and $\mathbf{e}$ is the regression error. In this case, forest cover increases (or decreases) linearly along the metropolitan gradient, satisfying the assumption of the mono-centric model [33]. To verify the possible impact of the varying size (i.e., surface area) of each spatial partition adopted as the elementary analysis' unit in this study (i.e., municipalities/urban districts), we run OLS linear estimations of Equation (1) both un-weighted and weighted with the surface area of each elementary unit $\left(\mathrm{km}^{2}\right)$. District area was the result of the application of an ArcGIS 'calculate area' tool on the shapefile depicting municipalities/urban districts provided by the National Institute of Statistics (ISTAT) and statistical office of Rome municipality (Figure 2, left).

A squared specification was also tested with the aim at defining a quadratic relationship of the metropolitan gradient on forest cover:

$$
F=a+b(D)+c\left(D^{2}\right)+e
$$

where $\mathrm{F}$ is the percent share of forest cover in the total landscape, $\mathrm{D}$ is the distance of each spatial unit from downtown Rome ( $\mathrm{km}$, log-transformed), a, b, and $\mathrm{c}$ are the regression coefficients, and $\mathbf{e}$ is the regression error. More complex patterns based on a cubic specification were tested to highlight place-specific responses of forest cover as the distance from downtown Rome increases [48], as follows:

$$
F=a+b(D)+c\left(D^{2}\right)+d\left(D^{3}\right)+e
$$

where $\mathrm{F}$ is the percent share of forest cover in the total landscape, $\mathrm{D}$ is the distance of each spatial unit from downtown Rome ( $\mathrm{km}$, log-transformed), a, b, c, and d are the regression coefficients, and $\mathbf{e}$ is the regression error. Significant specifications were assessed using standard diagnostics, namely the adjusted $\mathrm{R}^{2}$.

\subsubsection{Local Approaches}

We adopted a spatially explicit approach referring to the Geographically Weighted Regression (GWR) introduced by Fotheringham et al. (2002) to interpret complex spatial patterns of environmental and socioeconomic processes along a given geographical gradient. A refined understanding of the spatial variability related to the mono-centric expansion of metropolitan regions contributes to identify significant, local deviations from global patterns [48], informing spatial policies better adapted to specific territorial conditions. The use of administrative districts, such as municipalities, taken as policy-relevant spatial domains, allows a comprehensive investigation of context-based interactions that are frequently demised in 'centralized' (spatially implicit) interpretative models [51]. Based on these premises, GWRs estimate local regression models for each spatial domain in a given area, accounting for spatial dependence and heterogeneity [38], i.e., controlling for spatial structures that characterize the relationship between the dependent variable and the 
predictor (Ali et al., 2007). We adopted a standard GWR specification for a given location $\mathrm{s}=1$ to $\mathrm{n}$, as follows:

$$
\mathrm{F}(\mathrm{s})=\mathrm{B}(\mathrm{s}) \mathrm{D}(\mathrm{s})+\mathrm{e}(\mathrm{s})
$$

where $\mathrm{F}(\mathrm{s})$ and $\mathrm{D}(\mathrm{s})$ are, respectively, the dependent variable (percent forest cover) and the predictor (distance from downtown Rome) illustrated in Equation (1) above, which were both measured at each location s; B(s) means the column vector of the regression coefficients at location s, and $\mathbf{e}(\mathrm{s})$ is the random error at location s. Regression parameters were estimated separately for 1936 and 2018 at each location by weighted least squares and are thus spatially explicit, i.e., a function of s. Spatial coordinates of each elementary unit considered in this study were determined based on a shapefile map of administrative boundaries (see Figure 2, left) managed in ArcGIS (ESRI Inc., Redwoods, CA, USA) environment. A Kernel spline function was adopted to calculate weights for the estimation of local regressions [38]. Limitations regarding the use of GWR only arise when drawing conclusions based on a reduced number of sample observations, which is not the case of this study. GWRs were run separately for each time interval. For each regression, the model's results included (i) a global measure of goodness-of-fit (adjusted $R^{2}$ ) that was compared with the same index obtained from the respective OLS regression (both weighted and un-weighted for the surface area of each spatial partition, see above) and (ii) a spatial distribution of local coefficients ( $\mathrm{R}^{2}$, slope coefficient) illustrated through maps (Salvati et al. 2016). The GWR results clarify the role of spatial heterogeneity as a novel contribution to the empirical test of the mono-centric model [33].

The intrinsic shift from a classical 'mono-centric' model of forest expansion toward a more 'poly-centric' structure was reflected in a different spatial distribution of both slope and $R^{2}$ regression coefficients [16]. In fact, we expect (i) a more fragmented/heterogeneous distribution of $R^{2}$ coefficients (possibly indicating the increase in sparse nuclei of forest expansion) and (ii) an expansion of the spatial domains with high slope coefficients, reflecting a latent, but generalized, increase in forest cover [35]. With this perspective in mind, comparing the intensity and direction of the relationship between percent forest cover and the distance from downtown Rome for different econometric models and specifications (e.g., global vs. local, spatially implicit vs. spatially explicit) provides an intrinsic measure of the role of territorial factors [48]. Such contextual aspects should be more explicitly considered in any environmental policy targeting the mitigation of (and adaptation to) urbanization processes [49].

\section{Results}

Forest cover in Rome increased from 18.3\% in 1936 to $19.9 \%$ in 2018 . The spatial distribution of forest area (Figure 5) reflects the intense landscape transformations between 1936 and 2018, with forest expansion in relict croplands East of Rome and moderate decline in flat districts surrounding the 'Agro Romano' and along the sea coast. These districts included, up to now, the main remnants of the forest cover extending along the Tyrrhenian Sea coast from Tuscany to Campania in ancient times. Accelerated rates of forest recovery have been observed in rural, upland districts west and north of Rome, which were originally devoted to shrublands and olive groves (e.g., 'Sabina' district). Forest cover was relatively stable in the 'Castelli Romani' district, a peri-urban, upland area with high human pressure (population density around 500 inhabitants $/ \mathrm{km}^{2}$ ) and mostly devoted to chestnut production.

\subsection{Global Approaches}

All statistical models testing changes in the spatial relationship between forest cover and the distance from downtown Rome (Table 1) indicated how the correlation between the two variables intensified over time. Non-parametric Spearman rank coefficients delineate a positive and strong correlation between forest cover and distance from a central place in Rome $\left(r_{s}=0.76\right.$ and 0.86 , respectively for 1936 and 2018). However, while the first-order (linear) Ordinary Least Square (OLS) model performed rather low for 1936 and 2018, second- 
and third-order (i.e., squared and cubic) OLS regressions performed better for both years (adjusted $\mathrm{R}^{2}=0.58$ for 2018). With global $\mathrm{R}^{2}$ coefficients increasing from 0.65 in 1936 to 0.75 in 2018, local regressions outperformed OLS (linear and non-linear) models, documenting the importance of the spatial dimension in long-term forest transitions characteristic of the study area. Moran's spatial autocorrelation indexes demonstrate that the percent share of forest cover in the total municipal/district area was not randomly distributed over space (1936: $\mathrm{I}(z)=4.29, p<0.05 ; 2018: \mathrm{I}(z)=3.69, p<0.05)$. Spatial autocorrelation justifies the use of a local regression approach when assessing the relationship between percent share of forest cover in the total municipal/district area as the dependent variable and the distance from downtown Rome as an intrinsic test of the mono-centric (or poly-centric) forest structure.
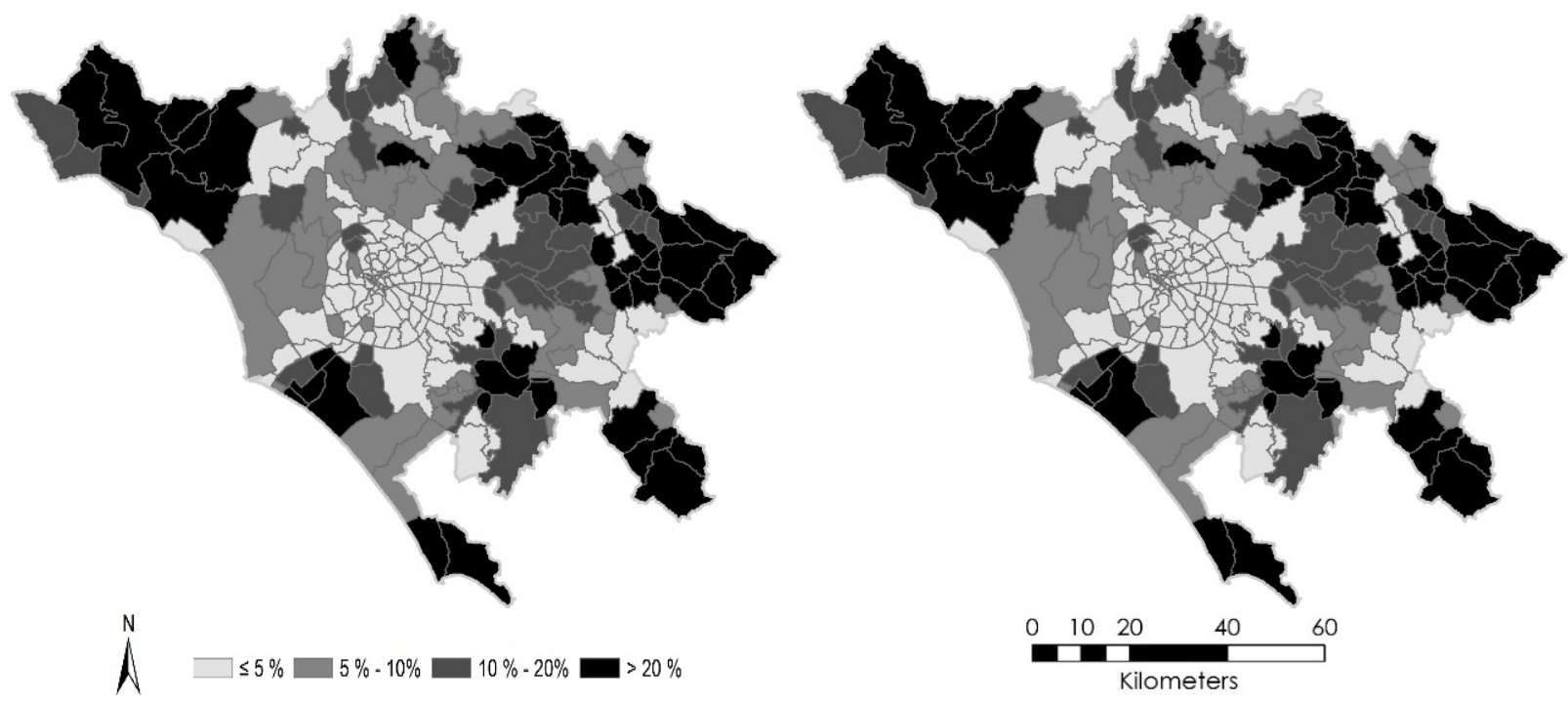

Figure 5. The spatial distribution of percent share of forest cover in the total municipal (or district) area in Rome (left: 1936; right: 2018).

Table 1. Correlation coefficients and best-fit $\mathrm{R}^{2}$ of global econometric models (Ordinary Least Squares (OLS) with linear and non-linear specifications; Geographically Weighted Regression (GWR) estimating the percentage of forest area in each spatial domain (dependent variable) from the distance to downtown Rome (predictor) by year.

\begin{tabular}{ccc}
\hline Model/Specification & $\mathbf{1 9 3 6}$ & $\mathbf{2 0 1 8}$ \\
\hline Pearson moment-product correlation & 0.616 & 0.750 \\
Non-parametric Spearman $r_{\mathrm{s}}$ rank correlation & 0.755 & 0.852 \\
Un-weighted, linear Ordinary Least Square (OLS) & 0.380 & 0.563 \\
Weighted, linear OLS t & 0.382 & 0.555 \\
Square (second-order polynomial) OLS & 0.402 & 0.573 \\
Cubic (third-order polynomial) OLS & 0.439 & 0.582 \\
Un-weighted Geographically Weighted Regression (GWR) & 0.643 & 0.769 \\
Weighted GWRt & 0.703 & 0.754
\end{tabular}

All models are significant at $p<0.05$. $\dagger$ weighted by surface area of each spatial domain (i.e., municipalities/urban districts).

\subsection{Local Approaches}

The satisfactory result of local regressions suggests how territorial contexts distinctive of municipalities and urban districts in the study area shape forest dynamics at different distances from downtown Rome. Local regressions modeled the spatial dimension of both 1936 and 2018 data by incorporating a location distance matrix that allowed the local estimation of both slope (measuring the predictor's impact) and $\mathrm{R}^{2}$ (measuring the model's goodness-of-fit) regression coefficients for each spatial domain. Vector maps were used 
to illustrate the spatial distribution of local regression slope and local $\mathrm{R}^{2}$ coefficients. The results of local regression models for forest cover as the dependent variable and the distance from downtown Rome as the predictor were illustrated in maps considering separately the spatial distribution of regression slopes and local $\mathrm{R}^{2}$ goodness-of-fit coefficients (Figure 6). Slope coefficients depicted the (more or less intense) contribution of specific areas to a mono-centric spatial structure.
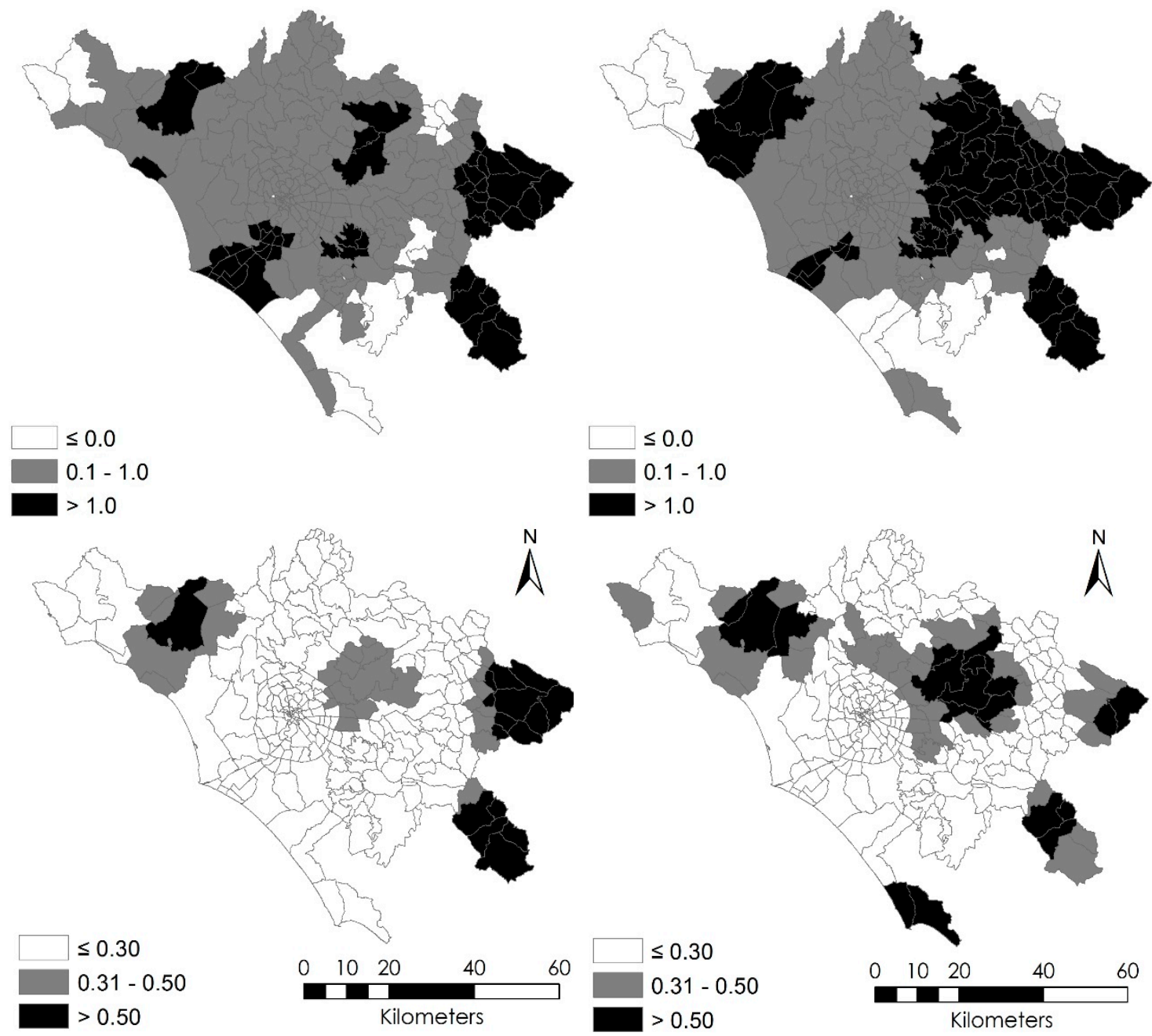

$>1.0$

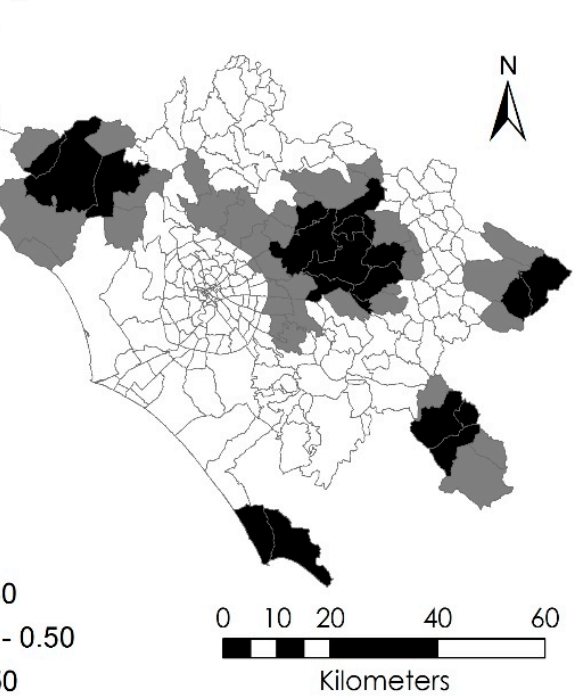

Figure 6. Results of a Geographically Weighted Regression assessing the relationship between the percent share of forest cover in total landscape and the distance from downtown Rome by year (left: 1936; right: 2018; upper panel: local slope (regression) coefficients; lower panel: local $\mathrm{R}^{2}$ goodness-of-fit coefficients).

The empirical results of local regressions indicate a distinctive spatial distribution of forest cover for 1936 and 2018, in turn reflecting a substantially different relationship with the distance from a central place in Rome. Comparing the models' goodness-of-fit, the regression for the last observation year (2018) was performing slightly better than the model for the first observation year (1936). Spatial units (municipalities/districts) with local $\mathrm{R}^{2}>0.5$ (regarded as a satisfactory model's fit at that spatial scale) increased during the study period. The spatial distribution of local $\mathrm{R}^{2}$ coefficients in 1936 delineated particularly high values in economically peripheral municipalities of the Apennine mountain districts ('Lucretili' and 'Lepini' districts), as well as in rural, remote municipalities in the northwest of Rome ('Tolfa-Bracciano' district). In 2018, the highest $\mathrm{R}^{2}$ coefficients were found either in upland/mountainous municipalities East of Rome ('Lucretili', 'Simbruini' and 'Lepini' districts); the same pattern was observed in sparse coastal/lowland municipalities featuring 
human disturbance and low ecological quality ('Anzio-Nettuno' coastal district South of Rome; 'Bracciano Lake' district). In both cases, spatial units with high $\mathrm{R}^{2}$ were found closer to Rome in 2018 than in 1936. As far as the impact of the distance from downtown, the highest regression slopes for 1936 were recorded in remote districts East of Rome and in more sparse flat areas close to the city. High slopes were also recorded in a rural, remote district West of Rome, and they decreased in intensity along the sea coast and in flat districts around the city. Eighty years later, while peripheral municipalities in the Apennine district still had the highest slope coefficients, more heterogeneous, peri-urban districts both west and east of Rome displayed high (or very high) slope coefficients. Taken together, local slope and $\mathrm{R}^{2}$ coefficients reflect the polarization in districts with forest recovery and decline, which is likely because of wildfires, clearcutting, or other human/ecological disturbances. The gradual disappearance of coastal woodlands because of progressive clearcutting made the spatial distribution of forests more heterogeneous, in turn contributing to a less polarized landscape in urban and rural areas. At the same time, urban sprawl and the rising human pressure driven by sprawled urbanization has consolidated some smaller nuclei of forest expansion, acting as an 'endogenous source' of forest transitions (i.e., fueling the shift from net decline to net recovery) at the local scale.

\section{Discussion}

During the last century, a significant decrease in cropland and a contemporary increase in residential settlements and forests has been observed in Italy [50] and, more generally, in Southern Europe [23]. Land-use change was responsible for the expansion of 'contact areas' between developed (i.e., residential and/or industrial settlements) and natural/seminatural landscapes in Mediterranean Europe [24,25,52,53]. By confirming the predictions of the Forest Transition Theory, our study documents the relevance of a comprehensive landscape analysis along urban-forest interfaces to inform policies containing urbanization and mitigating the negative impact of human disturbance on the surrounding natural habitats [7]. Barbati et al. (2013) found that the spatial distribution of natural landscapes in recent times became more polarized along the metropolitan continuum [5]. A thorough understanding of the intrinsic mechanisms of urban growth and the consequent dynamics of natural landscapes - mainly forests-along this gradient provides an integral vision and future perspective to landscape research [48]. From this perspective, our study contributes to regional science suggesting how the notion of mono-centric (or poly-centric) urban expansion can be (more or less directly) extended to dynamics related to other land use, namely forests, underlying socioeconomic mechanisms and territorial processes that are governed (and are in turn influenced by) the intrinsic linkage between humans and nature at the base of regional landscape dynamics [8]. A global analysis failed in assessing these complex dynamics, suggesting how spatially explicit approaches are appropriate tools to investigate the importance of heterogeneous local contexts [33], especially when they assume a stronger role than regional drivers of change and local socioeconomic pressures [9].

The results of local regressions presented in our study provided evidence on the importance of a mono-centric structure of urban growth in Rome, which is in line with the empirical findings of earlier studies [5,16,42] —as plastically illustrated in Figure 2 earlier in this paper with the parallel consolidation of a moderately polycentric model of forest expansion [35]. This complex spatial pattern is assumed to be the joint impact of two processes: (i) intense (natural) forestation in mountainous and economically depressed areas and (ii) moderate (and mostly human-induced) forest recovery in flat and coastal areas, depending on the intensity of conflicts over alternative land-use, i.e., on the basis of the 'economic strength' of the agricultural sector $[31,38,45,47]$. As a matter of fact, cropland abandonment typical of economically marginal districts was observed also in some periurban areas originally devoted to agriculture because of particularly fertile soils [51]. In such areas, forest expansion occurred more likely than in other socioeconomic contexts of the same geographical region $[5,39,48]$. 
Being representative of more general dynamics at the regional scale, distinctive transformations of peri-urban landscapes were described in the study area considering together the empirical results of this study and earlier literature: (i) economic decline of remote districts resulting in re-forestation [28,50,54], (ii) crop intensification in more accessible rural districts $[5,29,34]$, and (iii) urban sprawl, agricultural land consumption, and forest fragmentation in flat districts $[35,55,56]$. As a counter-intuitive result, forest increase was intrinsically associated with reduced proximity between settlements and natural land [51], as a result of forestation of abandoned cropland in accessible districts indirectly fueled by urban expansion [37-39]. From a socioeconomic standpoint, such transformations fueled the heterogeneous expansion of forest land cover [25], with ecosystem dynamics remaining essentially under-investigated [30].

From the spatial planning perspective, the results of our study highlight the need to adopt a multi-target strategy for the conservation of natural and semi-natural areas in peri-urban contexts [35]. This strategy should recognize forest expansion in peri-urban areas together as a positive process of greening [31] and a potentially negative phenomenon, as the increase in forest cover as well as in the length of the margin directly in contact with residential settlements causes an increased risk of wildfires in already vulnerable areas [47]. Future studies should better interpret long-term changes in metropolitan landscapes [37], clearly distinguishing the impact of socioeconomic drivers and planning/biophysical constraints to building, in turn clarifying the possible role of different forest and agroforest types in that change $[5,45,48]$. More generally, the analysis of changes in the forest landscape in peri-urban areas [46] cannot be separated from an accurate investigation of the causes of expansion and decline of agriculture in the facing rural contexts.

\section{Conclusions}

The present study refers to long-term changes in forest area that encompass a sufficiently long time period covering the productive cycle of a high forest. Long-term changes in forest cover include both natural and human-induced transformations and may account for a truly comprehensive picture of landscape changes. In this perspective, we tried to estimate the synergic impact of both drivers. The complex results of this study (i.e., the emergence of a polycentric model of forest expansion in a context of mono-centric expansion of urban settlements) outlines the urgent need for policy strategies managing urban-forest interactions along the fringe. Effective strategies governing peri-urban landscape dynamics should include (i) urban containment policies reducing the environmental impact of sprawl on fringe land and (ii) measures controlling the unwanted expansion of peri-urban woodlands (starting from the multiplication of a sort of 'hotspots' indirectly acting as nuclei of forest spread) at the expense of abandoned cropland.

Based on the empirical findings of this study and a pertinent review of the recent literature, these actions should target the integral preservation of the traditional diversity of agro-forest mosaics in Southern European fringe lands. Our study highlights the importance of monitoring techniques for the quantification of urban-forest ecosystem services, starting from a recent field experience in the Mediterranean context. New logical approaches and information technologies for the 'holistic' study of peri-urban forests are requested to integrate operational tools, methodologies, and analysis' techniques, with increasing, comparative evidence from case studies. Assessing the quality and health of peri-urban forests implies a reduction of monitoring costs, the improvement of sampling efficiency and accuracy, and a more effective integration of the existing measurement networks in a long-term vision that refers to the paradigms of ecological resilience and socioeconomic sustainability.

Author Contributions: Conceptualization, R.S. and G.Q.; methodology, L.S.; software, A.M.; validation, L.B. and G.E.; formal analysis, L.S.; investigation, R.S.; resources, G.Q.; data curation, G.E.; writing—original draft preparation, R.S.; writing—review and editing, L.S. and A.M.; visualization, L.B.; supervision, L.B.; project administration, A.M.; funding acquisition, G.Q. All authors have read and agreed to the published version of the manuscript. 
Funding: This research received no external funding.

Data Availability Statement: Official statistics derived from public websites were used in this study. Conflicts of Interest: The authors declare no conflict of interest.

\section{References}

1. Mather, A.S. Forest transition theory and the reforesting of scotland. Scott. Geogr. J. 2004, 120, 83-98. [CrossRef]

2. Perz, S.G. Grand theory and context-specificity in the study of forest dynamics: Forest transition theory and other directions. Prof. Geogr. 2007, 59, 105-114. [CrossRef]

3. Barbier, E.B.; Burgess, J.C.; Grainger, A. The forest transition: Towards a more comprehensive theoretical framework. Land Use Policy 2010, 27, 98-107. [CrossRef]

4. Meyfroidt, P.; Lambin, E.F. Global Forest Transition: Prospects for an End to Deforestation. Annu. Rev. Environ. Resour. 2011, 36, 343-371. [CrossRef]

5. Barbati, A.; Corona, P.; Salvati, L.; Gasparella, L. Natural forest expansion into suburban countryside: Gained ground for a green infrastructure? Urban For. Urban Green. 2013, 12, 36-43. [CrossRef]

6. Pagnutti, C.; Bauch, C.T.; Anand, M. Outlook on a Worldwide Forest Transition. PLoS ONE 2013, 8, e75890. [CrossRef]

7. Baines, O.; Wilkes, P.; Disney, M. Quantifying urban forest structure with open-access remote sensing data sets. Urban For. Urban Green. 2020, 50, 126653. [CrossRef]

8. Bonilla-Bedoya, S.; Mora, A.; Vaca, A.; Estrella, A.; Herrera, M.Á. Modelling the relationship between urban expansion processes and urban forest characteristics: An application to the Metropolitan District of Quito. Comput. Environ. Urban Syst. 2020, 79, 101420. [CrossRef]

9. Alvarez, S.; Soto, J.R.; Escobedo, F.J.; Lai, J.; Kibria, A.S.M.G.; Adams, D.C. Heterogeneous preferences and economic values for urban forest structural and functional attributes. Landsc. Urban Plan. 2021, 215, 104234. [CrossRef]

10. Rudel, T.K.; Coomes, O.T.; Moran, E.; Achard, F.; Angelsen, A.; Xu, J.; Lambin, E. Forest transitions: Towards a global understanding of land use change. Glob. Environ. Chang. 2005, 15, 23-31. [CrossRef]

11. Fagan, C.B.; Yackulic, M.; Jain, M.; Jina, A.; Lim, Y.; Marlier, M.; Muscarella, R.; Adame, P.; DeFries, R.; Uriarte, M. Biophysical and Socioeconomic Factors Associated with Forest Transitions at Multiple Spatial and Temporal Scale. Ecol. Soc. 2011, 16, 15. [CrossRef]

12. Mather, A.S.; Needle, C.L. The forest transition: A theoretical basis. Area 1998, 30, 117-124. [CrossRef]

13. Grainger, A. The Forest Transition: An Alternative Approach. Area 1995, 27, 242-251.

14. Mather, A.S.; Fairbairn, J. From floods to reforestation: The forest transition in Switzerland. Environ. Hist. Camb. 2000, 6, 399-421. [CrossRef]

15. van Vliet, J. Direct and indirect loss of natural area from urban expansion. Nat. Sustain. 2019, 2, 755-763. [CrossRef]

16. Salvati, L.; Ciommi, M.T.; Serra, P.; Chelli, F.M. Exploring the spatial structure of housing prices under economic expansion and stagnation: The role of socio-demographic factors in metropolitan Rome, Italy. Land Use Policy 2019, 81, 143-152. [CrossRef]

17. Plieninger, T.; Schaich, H.; Kizos, T. Land-use legacies in the forest structure of silvopastoral oak woodlands in the Eastern Mediterranean. Reg. Environ. Chang. 2011, 11, 603-615. [CrossRef]

18. Nowak, D.J.; Walton, J.T.; Dwyer, J.F.; Kaya, L.G.; Myeong, S.; Myeong, S. The Increasing Influence of Urban Environments on US Forest Management. J. For. 2005, 103, 377-382.

19. Kauppi, P.E.; Ausubel, J.H.; Fang, J.; Mather, A.S.; Sedjo, R.A.; Waggoner, P.E. Returning forests analyzed with the forest identity. Proc. Natl. Acad. Sci. USA 2006, 103, 17574-17579. [CrossRef]

20. Redo, D.J.; Grau, H.R.; Aide, T.M.; Clark, M.L. Asymmetric forest transition driven by the interaction of socioeconomic development and environmental heterogeneity in Central America. Proc. Natl. Acad. Sci. USA 2012, 109, 8839-8844. [CrossRef]

21. Rodríguez, L.G.; Pérez, M.R. Recent changes in Chinese forestry seen through the lens of Forest Transition theory. Int. For. Rev. 2013, 15, 456-470. [CrossRef]

22. Baptista, S.R.; Rudel, T.K. A re-emerging Atlantic forest? Urbanization, industrialization and the forest transition in Santa Catarina, southern Brazil. Environ. Conserv. 2006, 33, 195-202. [CrossRef]

23. Blondel, J.; Aronson, J.; Bodiou, J.-Y.; Boeuf, G. The Meditrerranean Region—Biological Diversity in Space and Time, 2nd ed.; Oxford University Press: Oxford, UK, 2010; ISBN 9780199557998.

24. Sirami, C.; Nespoulous, A.; Cheylan, J.P.; Marty, P.; Hvenegaard, G.T.; Geniez, P.; Schatz, B.; Martin, J.L. Long-term anthropogenic and ecological dynamics of a Mediterranean landscape: Impacts on multiple taxa. Landsc. Urban Plan. 2010, 96, 214-223. [CrossRef]

25. Vince, S.W.; Duryea, M.; Macie, E.A.; Hermansen, L.A. Forests at the Wildland-Urban Interface: Conservation and Management; CRC Press: Boca Raton, FL, USA, 2005; ISBN 9780367578213.

26. Stewart, S.I.; Radeloff, V.C.; Hammer, R.B.; Hawbaker, T.J. Defining the Wildland-Urban Interface. J. For. 2007, 105, $201-207$.

27. Endreny, T.A. Strategically growing the urban forest will improve our world. Nat. Commun. 2018, 9, 1160. [CrossRef] [PubMed]

28. Antrop, M. Changing patterns in the urbanized countryside of Western Europe. Landsc. Ecol. 2000, 15, 257-270. [CrossRef]

29. Antrop, M. Landscape change and the urbanization process in Europe. Landsc. Urban Plan. 2004, 67, 9-26. [CrossRef] 
30. Scarascia-Mugnozza, G.; Oswald, H.; Piussi, P.; Radoglou, K. Forests of the Mediterranean region: Gaps in knowledge and research needs. For. Ecol. Manag. 2000, 132, 97-109. [CrossRef]

31. Tomao, A.; Quatrini, V.; Corona, P.; Ferrara, A.; Lafortezza, R.; Salvati, L. Resilient landscapes in Mediterranean urban areas: Understanding factors influencing forest trends. Environ. Res. 2017, 156, 1-9. [CrossRef]

32. Bianchini, L.; Marucci, A.; Sateriano, A.; Di Stefano, V.; Alemanno, R.; Colantoni, A. Urbanization and long-term forest dynamics in a metropolitan region of southern europe (1936-2018). Sustainability 2021, 13, 12164. [CrossRef]

33. Salvati, L.; Carlucci, M. Distance matters: Land consumption and the mono-centric model in two southern European cities. Landsc. Urban Plan. 2014, 127, 41-51. [CrossRef]

34. Salvati, L.; Zitti, M. Territorial disparities, natural resource distribution, and land degradation: A case study in southern Europe GeoJournal 2007, 70, 185-194. [CrossRef]

35. Colantoni, A.; Mavrakis, A.; Sorgi, T.; Salvati, L. Towards a 'polycentric' landscape? Reconnecting fragments into an integrated network of coastal forests in Rome. Rend. Lincei 2015, 3, 615-624. [CrossRef]

36. Çakir, G.; Ün, C.; Baskent, E.Z.; Köse, S.; Sivrikaya, F.; Keleş, S. Evaluating urbanization, fragmentation and land use/land cover change pattern in Istanbul city, Turkey from 1971 to 2002. Land Degrad. Dev. 2008, 19, 663-675. [CrossRef]

37. Pili, S.; Grigoriadis, E.; Carlucci, M.; Clemente, M.; Salvati, L. Towards sustainable growth? A multi-criteria assessment of (changing) urban forms. Ecol. Indic. 2017, 76, 71-80. [CrossRef]

38. Duvernoy, I.; Zambon, I.; Sateriano, A.; Salvati, L. Pictures from the other side of the fringe: Urban growth and peri-urban agriculture in a post-industrial city (Toulouse, France). J. Rural Stud. 2018, 57, 25-35. [CrossRef]

39. Perrin, C.; Nougarèdes, B.; Sini, L.; Branduini, P.; Salvati, L.; Perrin, C.; Nougarèdes, B.; Sini, L.; Branduini, P.; Salvati, L. Governance changes in peri-urban farmland protection following decentralisation: A comparison between Montpellier (France) and Rome (Italy). Land Use Policy 2018, 70, 535-546. [CrossRef]

40. Žlender, V. Characterisation of peri-urban landscape based on the views and attitudes of different actors. Land Use Policy 2021, 101, 105181. [CrossRef]

41. Di Feliciantonio, C.; Salvati, L.; Sarantakou, E.; Rontos, K. Class diversification, economic growth and urban sprawl: Evidences from a pre-crisis European city. Qual. Quant. Int. J. Methodol. 2018, 52, 1501-1522. [CrossRef]

42. Ciommi, M.; Chelli, F.M.; Carlucci, M.; Salvati, L. Urban Growth and Demographic Dynamics in Southern Europe: Toward a New Statistical Approach to Regional Science. Sustainability 2018, 10, 2765. [CrossRef]

43. Theobald, D.M.; Romme, W.H. Expansion of the US wildland-urban interface. Landsc. Urban Plan. 2007, 83, 340-354. [CrossRef]

44. Bianchini, L.; Egidi, G.; Alhuseen, A.; Sateriano, A.; Cividino, S.; Clemente, M.; Imbrenda, V. Toward a dualistic growth? Population increase and land-use change in Rome, Italy. Land 2021, 10, 749. [CrossRef]

45. Ferrari, B.; Corona, P.; Mancini, L.D.; Salvati, R.; Barbati, A. Taking the pulse of forest plantations success in peri-urban environments through continuous inventory. New For. 2017, 48, 527-545. [CrossRef]

46. Camarretta, N.; Puletti, N.; Chiavetta, U.; Corona, P. Quantitative changes of forest landscapes over the last century across Italy. Plant Biosyst. 2017, 152, 1011-1019. [CrossRef]

47. Grotti, M.; Mattioli, W.; Ferrari, B.; Tomao, A.; Merlini, P.; Corona, P. A multi-temporal dataset of forest mensuration of reforestations: A case study in peri-urban Rome, Italy. Ann. Silvic. Res. 2019, 43, 97-101. [CrossRef]

48. Pili, S.; Serra, P.; Salvati, L. Landscape and the city: Agro-forest systems, land fragmentation and the ecological network in Rome, Italy. Urban For. Urban Green. 2019, 41, 230-237. [CrossRef]

49. Biasi, R.; Brunori, E.; Smiraglia, D.; Salvati, L. Linking traditional tree-crop landscapes and agro-biodiversity in central Italy using a database of typical and traditional products: A multiple risk assessment through a data mining analysis. Biodivers. Conserv. 2015, 24, 3009-3031. [CrossRef]

50. Falcucci, A.; Maiorano, L.; Boitani, L. Changes in land-use/land-cover patterns in Italy and their implications for biodiversity conservation. Landsc. Ecol. 2007, 22, 617-631. [CrossRef]

51. Cecchini, M.; Zambon, I.; Pontrandolfi, A.; Turco, R.; Colantoni, A.; Mavrakis, A.; Salvati, L. Urban sprawl and the 'olive' landscape: Sustainable land management for 'crisis' cities. GeoJournal 2019, 84, 237-255. [CrossRef]

52. Zipperer, W.C. Species composition and structure of regenerated and remnant forest patches within an urban landscape. Urban Ecosyst. 2002, 6, 271-290. [CrossRef]

53. Foley, J.A.; DeFries, R.; Asner, G.P.; Barford, C.; Bonan, G.; Carpenter, S.R.; Chapin, F.S.; Coe, M.T.; Daily, G.C.; Gibbs, H.K.; et al. Global consequences of land use. Science 2005, 309, 570-574. [CrossRef] [PubMed]

54. Bajocco, S.; Dragoz, E.; Gitas, I.; Smiraglia, D.; Salvati, L.; Ricotta, C. Mapping Forest Fuels through Vegetation Phenology: The Role of Coarse-Resolution Satellite Time-Series. PLoS ONE 2015, 10, e0119811. [CrossRef]

55. Attorre, F.; Bruno, M.; Francesconi, F.; Valenti, R.; Bruno, F. Landscape changes of Rome through tree-lined roads. Landsc. Urban Plan. 2000, 49, 115-128. [CrossRef]

56. Cavallo, A.; Marino, D. Understanding Changing in Traditional Agricultural Landscapes: Towards a Framework. J. Agric. Sci. Technol. 2012, 2, 971-978. 